\title{
Experimentos de pensamento como recurso pedagógico para o ensino de Filosofia
}

\author{
Thought experiments as a pedagogical resource \\ for teaching of Philosophy
}

\author{
Luana Francine Nyland \\ Mestranda na Universidade Federal de Santa Catarina, Florianópolis, Santa Catarina, Brasil. \\ luana.nyland@hotmail.com - https://orcid.org/0000-0003-3884-5837
}

Recebido em 22 de novembro de 2019

Aprovado em 13 de abril de 2019

Publicado em 30 de julho de 2020

RESUMO: Este trabalho tem como objeto de investigação uma ferramenta metodológica muito utilizada na Filosofia, experimentos de pensamento. Os experimentos de pensamento são narrativas que convidam o leitor a imaginar e avaliar uma situação hipotética, sendo utilizados na investigação filosófica para elucidar determinada concepção ou, até mesmo, para apoiar ou refutar alguma teoria. Contudo, poderia essa ferramenta de investigação ser utilizada também como um recurso pedagógico nas aulas de Filosofia? O objetivo desse trabalho consiste em defender uma resposta positiva a tal pergunta. Para isso, apresento a perspectiva de Nancy J. Nersessian (1992, 2018) sobre o raciocínio envolvido na experimentação mental, que é baseada na perspectiva de modelos mentais (mental models), para apoiar a hipótese de que experimentos de pensamento podem ser utilizados como recursos pedagógicos no ensino de Filosofia.

Palavras-chave: Ensino de Filosofia; experimentos de pensamento; recurso pedagógico; modelos mentais.

ABSTRACT: The paper analyses a widely used tool in philosophical methodology, thought experiments. Thought experiments are narratives that invite the reader to imagine and evaluate a hypothetical situation. They are used in philosophical inquiry to clarify a certain conception, and even to support or refute some theory. However, could this research tool also be used as a pedagogical resource in Philosophy classes? The aim of this paper will be to support a positive answer to this question. For this, I present Nancy J. Nersessian's perspective on the reasoning involved in thought experimenting, which is based on mental models perspective, to support the hypothesis that thought experiments can be used as pedagogical resources in the teaching of Philosophy.

Keywords: Teaching of Philosophy; thought experiments; pedagogical resource; mental models.

\section{Introdução}

Ensinar Filosofia não é uma tarefa fácil. Seus problemas e conceitos, com os quais lidamos diariamente, muitas vezes sem percebermos, parecem tão abstratos e distantes quando apresentados aos alunos do ensino básico. $E$, aqui, não estou pensando em uma aula de Filosofia em que o professor perambula entre termos como 'ontologia', 'metafísica', 'epistemologia', 'ceticismo', 'utilitarismo', 'superveniência', 'determinismo', entre outros. 
Estou considerando, sem pressupor nenhuma teoria de fundo, conceitos mais básicos que fazem parte do nosso cotidiano, como 'liberdade', 'ser', 'conhecimento', 'racional' ou 'correto', por exemplo. Como esses conceitos aparecem nas nossas relações e ações diárias? Como lidamos com eles? Como podemos defini-los? Quais os problemas que surgem quando tais conceitos estão em jogo? Perguntas como essas, quando realizadas assim, de forma brusca, podem não produzir um diálogo produtivo com uma turma de jovens que tiveram pouco ou nenhum contato com a Filosofia e suas questões de modo geral. Quando não conseguimos trazer esses conceitos simples para o terreno comum dos alunos, eles também não conseguem manipular tais conceitos com seus conhecimentos de fundo. Fica aquela situação embaraçosa em que o professor até tenta fazer com que a turma interaja com o conteúdo que ele pretende trabalhar por meio de perguntas e questionamentos, mas a resposta surge em forma de silêncio e olhares perdidos em meio ao constrangimento da incompreensão daquilo que está sendo proposto.

Como podemos esperar que os alunos aprendam, ou ainda, compreendam algo novo a partir de perguntas e discussões abstratas ou distantes da realidade deles? Que recursos podemos utilizar nas aulas de Filosofia que podem contribuir para uma introdução dos alunos aos problemas filosóficos, que permitam uma aproximação menos abstrata aos conceitos envolvidos, e que, de alguma forma, também contribuam para a compreensão da própria Filosofia? A minha resposta a tal pergunta volta-se a uma ferramenta metodológica muito utilizada nas investigações filosóficas: experimentos de pensamento. Acredito que essa ferramenta metodológica também possa ser utilizada como um recurso pedagógico nas aulas de Filosofia para aproximar os alunos dos problemas filosóficos e permitir que eles lidem com os conceitos envolvidos por meio da manipulação e experimentação mental.

Não precisamos ir muito longe para encontrarmos experimentos de pensamento sendo utilizados na Filosofia. "Imagine a seguinte situação...", "Suponha que...", "Considere a hipótese...", "Pense sobre o seguinte cenário...", são vários os modos de como eles aparecem nos textos filosóficos. Os experimentos de pensamento assumem a forma de narrativas que convidam o leitor a imaginar e avaliar uma situação hipotética. Filósofos fazem uso dessa ferramenta para elucidar alguma determinada concepção ou, até mesmo, para apoiar ou refutar alguma teoria. Nesse sentido, olhar para a Filosofia e desconsiderar o uso dessa ferramenta faz com que deixemos de fora grande parte da investigação que essa área desenvolveu durante seus mais de dois mil anos de história. Muitas das discussões e problemas filosóficos estão alicerçados em experimentos de pensamento e muito do que se faz atualmente na Filosofia é fruto do uso deliberado da imaginação. Estudar Filosofia e não esbarrar com algum caso hipotético, com algum cenário contrafactual, ou mesmo com uma situação imaginária parece ser algo improvável. Desse modo, pensar o seu ensino sem apresentar, ou mesmo utilizar tal ferramenta com os alunos, faz com estes não entrem em contato com uma boa parcela daquilo que é feito em Filosofia.

Levando isso em consideração, investigo em que medida utilizar experimentos de pensamento como um recurso pedagógico pode trazer uma contribuição para as aulas de Filosofia do ensino básico. Para tal, na primeira parte do trabalho, busco traçar uma breve 
apresentação do que são experimentos de pensamento e como eles são utilizados na Filosofia, bem como apresento alguns dos exemplos mais conhecidos na comunidade filosófica. A segunda parte da minha investigação volta-se a compreender como os experimentos de pensamento funcionam e como através deles podemos melhorar a compreensão de determinada concepção, ou até mesmo, obter novos conhecimentos sobre o mundo. Para isso, apresento a tese proposta por Nancy J. Nersessian $(1992,2018)$ de que o raciocínio por meio de um experimento de pensamento envolve a construção e a simulação de um modelo mental da situação descrita na narrativa e que através da manipulação desse modelo podemos obter novas informações sobre o mundo. Por fim, na terceira parte do trabalho, pretendo relacionar as conclusões apresentadas por Nersessian $(1992,2018)$ com a minha hipótese de que utilizar experimentos de pensamento nas aulas de Filosofia pode contribuir na aproximação dos alunos aos problemas e compreensão dos conceitos envolvidos nas discussões filosóficas, uma vez que, ao executarem um experimento de pensamento os alunos estariam criando modelos mentais da situação descrita no experimento e a partir disso relacionando seus próprios conhecimentos na construção e compreensão de tal modelo. Desse modo, acredito que por meio da experimentação mental os alunos podem alcançar conclusões e compreensões dos problemas e conceitos filosóficos mais facilmente do que em relação a uma abordagem mais direta e abstrata, em que os problemas e conceitos são apenas apresentados aos alunos em uma aula de Filosofia puramente histórica e expositiva.

\section{Experimentos de Pensamento na Filosofia}

O termo "experimento de pensamento" (thought experiment) foi mencionado pela primeira vez em um artigo de 1811, de Hans Christian Ørsted ${ }^{1}$, contudo foi Ernst Mach, em 1897, que trouxe o termo thought experiment (ou ainda, Gedankenexperiment) para a discussão filosófica ${ }^{2}$. Historicamente, seu papel é muito próximo ao realizado por experimentos e observações laboratoriais reais, porém para realizarmos um experimento de pensamento não precisamos de laboratório nem instrumentos reais. Podemos dizer que, neste caso, o nosso laboratório é a mente e o instrumento utilizado para a realização do experimento é o pensamento. Nesse sentido, os experimentos de pensamentos são comumente encontrados na Filosofia em forma de narrativas que convidam o leitor a imaginar uma situação hipotética e visam extrair respostas desse processo imaginativo. Tais respostas são tomadas para elucidar determinado ponto, ou até mesmo, para corroborar ou refutar alguma perspectiva.

Podemos considerar que os experimentos de pensamento, de modo geral, possuem uma certa estrutura, conforme apresentada por Tamar Szabó Gendler (1996):

(1) Um cenário imaginário é descrito.

(2) É oferecido um argumento que tenta estabelecer a avaliação correta do cenário.

(3) Esta avaliação do cenário imaginado é então levada a revelar algo sobre casos além do cenário ( $p .37$ ). 
Além dessa estrutura que caracteriza, ainda que de modo genérico, um experimento de pensamento e possibilita que o identifiquemos, existem diferentes tipos de tais experimentos. Para diferenciá-los basta olharmos para as diferentes perguntas que podem ser feitas sobre um cenário imaginário que é proposto: O que aconteceria? Como devemos descrever o que aconteceria? Como devemos avaliar o que aconteceria? A partir da primeira pergunta, Gendler (1996, p. 42) sugere que podemos chamar o primeiro tipo de experimento de pensamento de factivo (factive), sobre o que pensamos que os fatos de uma situação seriam; a partir da segunda pergunta, o segundo tipo seria conceitual (conceptual), sobre o que consideramos ser a aplicação adequada de conceitos; e com a terceira pergunta temos o terceiro tipo que a autora chama de valorativo (valuational), sobre a resposta moral ou estética adequada a uma situação. Experimentos de pensamento factivos tendem a ser desenvolvidos na investigação científica, já os experimentos do tipo conceitual e valorativo tendem a ser desenvolvidos na investigação filosófica.

Outro modo de compreendermos o que é um experimento de pensamento pode dar-se, de acordo com Gendler (2010, p. 2), ao compará-los com experimentos reais, aqueles desenvolvidos pela ciência. Enquanto a execução de um experimento de pensamento é guiada pela imaginação e manipula representações mentais, experimentos reais lidam com o mundo físico e manipulam propriedades do mundo observado. O objetivo dos experimentos reais é realizar testes empíricos em condições controladas visando apoiar, refutar ou validar uma hipótese. E quando refletimos sobre um cenário imaginário estamos perseguindo esses mesmos objetivos. Na ciência, os dados relativos ao comportamento do mundo físico, advindos da experimentação real, são apontados como evidências para a teoria em discussão. Entretanto, Gendler (2010) afirma que, no caso dos experimentos de pensamento, as evidências assumem a forma de intuições sobre o comportamento daquilo que está sendo avaliado. Nesse sentido, por meio da experimentação mental ou real é possível atingirmos certas conclusões, ou ainda intuições, que apoiam as teorias que estão em discussão. Vejamos alguns exemplos de experimentos de pensamento encontrados na Filosofia e as conclusões, ou intuições, que são obtidas por meio da sua experimentação.

Contraexemplos de Gettier: Os experimentos de pensamento propostos por Edmund Gettier (1963) podem ser considerados uns dos mais discutidos na Filosofia contemporânea. Através desses contraexemplos, Gettier (1963) apontou para a insuficiência das condições estabelecidas pela definição tradicional de conhecimento que exigia do conhecedor a posse de uma crença verdadeira e justificada. Eis um dos dois experimentos de pensamento apresentados por Gettier (1963, p. 122):

Suponha-se que Smith e Jones tenham se candidatado a um certo emprego. E suponha-se que Smith tem fortes provas a favor da seguinte proposição conjuntiva:

(d) Jones é o homem que vai conseguir o emprego, e Jones tem dez moedas no bolso. 
As provas que Smith tem a favor de (d) podem ser que o presidente da companhia Ihe tenha assegurado que no fim Jones seria selecionado e que ele, Smith, tenha contado as moedas do bolso de Jones há dez minutos. A proposição (d) implica:

(e) O homem que vai ficar com o emprego tem dez moedas no bolso.

Suponha-se que Smith vê que (d) implica (e) e que aceita (e) com base em (d), a favor da qual ele tem fortes provas. Neste caso, Smith está claramente justificado em acreditar que (e) é verdadeira. Mas imagine-se que, além disso, sem Smith o saber, é ele e não Jones que vai ficar com o emprego. Imagine-se também que, sem o saber, ele próprio tem dez moedas no bolso. A proposição (e) é assim verdadeira, apesar de a proposição (d), a partir da qual Smith inferiu (e), ser falsa. Assim, no nosso exemplo, as seguintes proposições são verdadeiras: i) (e) é verdadeira, ii) Smith acredita que (e) é verdadeira e iii) Smith está justificado a acreditar que (e) é verdadeira. Mas é igualmente claro que Smith não sabe que (e) é verdadeira; pois (e) é verdadeira em virtude das moedas que estão no bolso de Smith, ao passo que Smith não sabe quantas moedas tem no bolso e baseia a sua crença em (e) no facto de ter contado as moedas do bolso de Jones, que ele erradamente acredita tratar-se do homem que irá ficar com o emprego.

A cientista Mary: O experimento de pensamento de Frank Jackson (1982) contra o fisicalismo (tese que considera que tudo, inclusive o mental, é físico) também gerou um grande debate na Filosofia. Jackson (1982) pretendeu mostrar com seu experimento de pensamento que nenhuma informação física captura os aspectos subjetivos da experiência, ou seja, que nenhuma informação física é capaz de explicar completamente as nossas sensações. Segue como Jackson (1982, p. 130, grifos do autor) apresentou o caso de Mary:

Mary é uma cientista brilhante que, por qualquer razão, é forçada a investigar o mundo a partir de um quarto preto e branco através de um monitor de televisão preto e branco. Ela é especializada em neurofisiologia da visão e adquire, suponha, toda a informação física que existe sobre o que acontece quando vemos tomates maduros, ou o céu, e usamos termos como "vermelho", "azul", e assim por diante. Ela descobre, por exemplo, exatamente quais combinações de comprimento de onda do céu estimulam a retina, e exatamente como isso produz, através do sistema nervoso central, a contração das cordas vocais e a expulsão de ar dos pulmões que resulta no proferimento da sentença 'O céu é azul'. (Dificilmente se pode negar que, em princípio, é possível obter toda essa informação física da televisão em preto e branco, caso contrário, a Universidade Aberta precisaria, necessariamente, usar a televisão em cores). O que acontecerá quando Mary for liberada de seu quarto preto e branco ou receber um monitor colorido de televisão? Ela aprenderá alguma coisa ou não? Parece óbvio que ela aprenderá algo sobre o mundo e nossa experiência visual. Mas então é inevitável que seu conhecimento anterior tenha sido incompleto. Mas ela tinha toda a informação física. Logo, há mais a ter do que isso, e o fisicalismo é falso. 
Trolley problems: Um dos tipos de experimentos de pensamento mais discutidos em filosofia moral contemporânea são os famosos trolley problems, ou ainda, "problemas do bondinho". Tais experimentos de pensamento foram primeiramente apresentados por Philippa Foot (1978) e posteriormente também elaborados por Judith Jarvis Thompson (1985) e inúmeros autores. Apresento uma passagem em que Thompson (1985, p. 1395) descreve uma versão do problema:

Philippa Foot chamou atenção para um problema extraordinariamente
interessante. Suponha que você seja o condutor de um bondinho. O
bondinho faz uma curva e lá surgem em vista cinco trabalhadores
de trilhos, que estão consertando a pista. A pista passa por uma
espécie de vale naquele ponto e os lados são íngremes, então
você deve parar o bondinho para evitar jogar os cinco homens
abaixo. Você pisa nos freios, mas infelizmente eles não funcionam.
Agora de repente você vê uma ramificação de pista que vai para
a direita. Você pode virar o bondinho para ela e assim salvar os
cinco homens na pista reta à frente. Infelizmente, a Sra. Foot
organizou as coisas para que haja um trabalhador de trilhos nesta
ramificação de pista. Ele não consegue sair da pista a tempo, assim
como os cinco também não, então você vai matá-lo se você virar o
bondinho para ele. É moralmente permissível você virar o bondinho?
Todo mundo a quem apresentei este caso hipotético diz, sim, é.

Alguns outros exemplos facilmente reconhecíveis de experimentos de pensamento na Filosofia são: o experimento da Terra Gêmea de Hilary Putnam (1975), o experimento do Zumbi de David Chalmers (1996), o experimento do quarto chinês de John Searle (1980), o experimento do Violinista de Judith Thomson (1971) e o experimento de John Rawls (1971) para o conceito de justiça. Apesar desses exemplos serem contemporâneos, encontramos também experimentos de pensamento já no pensamento antigo, assim como em obras de filósofos medievais e modernos ${ }^{3}$. Parece, então, que, independentemente da área ou época em que a pesquisa filosófica encontra-se, é provável que o filosofar exija, em alguns momentos, construir casos hipotéticos e fazer julgamentos sobre eles.

Quando nos deparamos com esses e outros experimentos de pensamento somos convidados a refletir sobre uma situação nova e emitir um julgamento sobre essa situação. Essa reflexão, ou ainda, esse raciocínio que realizamos por meio da experimentação mental permite considerarmos aspectos que, até então, não havíamos considerados. Ao analisarmos o cenário, os sujeitos e os eventos envolvidos nesse cenário, estamos relacionando nossos conhecimentos de fundo, conceitos e pressupostos de um modo que muitas vezes não fazemos cotidianamente. Isso nos leva, muitas vezes, a adquirirmos informações, ou mesmo, conhecimentos que não tínhamos antes de realizarmos tal experimentação mental. Dessa forma, o que torna os experimentos de pensamento algo instigante é o fato de que, por meio deles, parece ser possível adquirirmos novos conhecimentos apenas refletindo sobre um cenário imaginário, apenas pensando. Não precisamos de nenhum dado empírico para 
atingirmos determinadas conclusões, podendo essas serem conclusões sobre o próprio mundo físico. Como uma ferramenta de investigação, que é operada apenas por meio da imaginação, por meio do pensamento, pode ser capaz de gerar novos conhecimentos contingentes sobre o mundo? ${ }^{4}$ Alguns filósofos sugeriram perspectivas que buscam explicar a capacidade informativa dos experimentos de pensamento ${ }^{5}$. Entretanto, considero a seguir apenas uma abordagem que acredito oferecer uma boa explicação sobre como raciocinamos por meio dos experimentos de pensamento e como podemos obter novos conhecimentos a partir disso.

\section{Experimentação e modelagem mental}

A abordagem que parece proporcionar uma boa explicação de como raciocinamos por meio de experimentos de pensamento é oferecida por Nancy J. Nersessian (1992, 2018). A autora trabalha com a hipótese de que uma experiência de pensamento é uma forma de modelagem mental, uma espécie de raciocínio enraizado na nossa capacidade de antecipar, visualizar, imaginar e reexperimentar da memória (NERSESSIAN, 2018, p. 310). Desse modo, experimentos de pensamento utilizam a capacidade humana para o pensamento imaginativo. Tal capacidade para explorar mentalmente situações reais e imaginárias é algo presente há muito tempo nos seres humanos e acredita-se que ela tenha se desenvolvido na medida em que seria altamente adaptativo conseguir antecipar situações e prever possíveis resultados das ações de outros animais. Essa hipótese é apontada pelo psicólogo e fisiologista Kenneth Craik (1943), o qual considera a simulação mental como central para o nosso modo de raciocinar. Para Craik (1943), criamos modelos internos (modelos mentais) em pequena escala da realidade externa para predizer o ambiente e planejar ações futuras. Tais modelos representariam, de forma equivalente, a estrutura, o comportamento e a função de fenômenos do mundo real. E é em sua obra que surge primeiramente a noção de "modelo mental" (mental model), que posteriormente aparece em pesquisas independentes das ciências cognitivas, e que Nersessian $(1992,2018)$ acredita estar por trás do modo como raciocinamos por meio de experimentos de pensamento.

Nersessian (1992, p. 291) sugere que o raciocínio que realizamos em uma experiência de pensamento é baseado em modelos simulativos (simulative model-based reasoning). Em outras palavras, quando somos apresentados a um experimento de pensamento imaginamos a sequência de eventos e processos descritos na narrativa em questão e, para isso, construímos modelos dinâmicos na mente e manipulamos tais modelos visando extrair inferências a partir dessa simulação mental. Nesse sentido, experimentos de pensamento seriam distintos de argumentos lógicos e de outros modos de raciocínio proposicional, pois as conclusões alcançadas não ocorreriam através de inferências lógicas, mas por meio da manipulação mental.

Nersessian (1992) aponta algumas das linhas de pesquisa que investigam as noções teóricas de "modelo mental" e "modelagem mental" na literatura das ciências cognitivas. Duas das principais investigações são aquelas que consideram, por um lado, os modelos 
mentais como sendo estruturas armazenadas na memória de longo prazo que são posteriormente utilizadas no raciocínio, e aquelas que consideram os modelos mentais como sendo estruturas temporárias construídas na memória de trabalho para uma tarefa específica de raciocínio (NERSESSIAN, 1992, p. 293). Contudo, a autora considera em sua hipótese apenas os estudos que trazem a ideia de que no raciocínio estão envolvidos a construção e manipulação de um modelo na memória de trabalho e não os estudos que se voltam à natureza da representação na memória de longo prazo. Um dos principais autores que abordam esse relato da memória de trabalho na modelagem mental é Philip Johnson-Laird (1983) em sua obra Mental Models. Embora o autor tenha voltado a sua abordagem para a modelagem mental em tarefas de raciocínio dedutivo e indutivo, e não no domínio dos experimentos de pensamento, Nersessian (2018) ressalta que sua obra tem uma grande influência e oferece uma explicação geral dos modelos mentais enquanto estruturas de raciocínio temporário.

Um experimento de pensamento é geralmente construído e apresentado em forma de narrativas e, conforme a autora, uma narrativa é um modo pelo qual produzimos um modelo mental na memória de trabalho. Nersessian (2018, p. 313) aponta que há um grande número de pesquisas cognitivas defendendo a ideia de que quando lemos, raciocinamos e compreendemos uma história estamos fazemos inferências que são derivadas da construção e manipulação de um modelo mental da situação descrita pela narrativa. Nesse caso, não estaríamos aplicando regras de inferências com as proposições que representam o conteúdo do texto, pois apesar de usarmos a linguagem para construir uma narrativa, as operações envolvidas na experimentação mental não se dariam por meio de representações linguísticas, mas através de modelos que a narrativa nos permitiu construir (NERSESSIAN, 1992, p. 292). A ideia é que as expressões linguísticas presentes em uma narrativa auxiliam a construção de um modelo mental pelo qual o leitor, ou o ouvinte, compreende e raciocina sobre a situação representada. Desse modo, o referente do texto seria um modelo interno da situação representada pelo texto, em vez de uma descrição interna. Esse modelo do discurso criado por meio de uma narrativa, assim como um modelo mental, incorpora a representação das relações espaciais e temporais, bem como as estruturas causais dos eventos e entidades descritos na narrativa. Isso é possível na medida em que o leitor recorre a uma combinação de conhecimento conceitual e conhecimento real, tácito e explícito, bem como emprega os mecanismos de inferência do seu aparto cognitivo para construir, manipular e atualizar tal modelo (NERSESSIAN, 2018, p. 313).

A autora ainda aponta alguns estudos que reforçam a ideia de que o raciocínio por meio da manipulação mental permite que o leitor faça inferências mais rapidamente quando comparado com argumentos da forma proposicional (NERSESSIAN, 2018, p. 313). Isso porque o leitor chega a uma determinada conclusão sem precisar executar operações extensas que um argumento proposicional demanda ao processar a mesma quantidade de informação de fundo requerida por um experimento de pensamento. As conclusões que obtemos por meio de experimentos de pensamento surgem de forma rápida e espontânea, o que nos faz pressupor, assim como Nersessian (2018), que o raciocínio que realizamos ao executarmos um experimento de pensamento não possa dar-se por meio de inferências proposicionais, pois isso demandaria um recurso cognitivo com um custo muito elevado para 
o seu processamento. Nessa perspectiva, quando o leitor depara-se com uma narrativa, ele constrói espontaneamente um modelo mental para representar e raciocinar sobre a situação apresentada no texto, e, com isso, compreende a narrativa e extrai conclusões mais rapidamente do que se fosse o caso de ele ter que realizar o mesmo processo inferencial através de um argumento na forma proposicional.

A criação de modelos mentais não se restringe às descrições de narrativas, pois também criamos modelos a partir da percepção. É bem provável que, antes mesmo do homem desenvolver a linguagem, ele já manipulava modelos mentais por meio de dados perceptivos. A modelagem mental, como mencionado anteriormente, fez parte da nossa evolução, uma vez que, por meio dela, o ser humano utilizava a capacidade de antecipar, visualizar, imaginar e reexperimentar da memória para explorar mentalmente situações reais e imaginárias e, com isso, conseguir antecipar situações para planejar as suas ações futuras. Nersessian (1992, p. 294) cita pesquisas em neuropsicologia que trazem evidências de que nosso sistema perceptivo parece também desempenhar um papel significativo no raciocínio imaginativo de modo geral. Isso porque, a partir de uma perspectiva evolucionista, o córtex visual é uma das regiões mais antigas e desenvolvidas do nosso cérebro. A autora cita o psicólogo Roger Shephard que, ao realizar extensa pesquisa sobre cognição visual, concluiu a partir de suas investigações que a imaginação seria mais parecida com a visualização do que com a fala ou com o próprio cálculo matemático (NERSESSIAN, 1992, p. 294). Contudo, Nersessian (1992) enfatiza que, mesmo usando mecanismos do córtex visual, a modelagem mental não é como construir uma imagem na mente, dessa forma ela afirma que "a modelagem mental não requer acesso introspectivo a uma imagem no 'olho da mente'. Requer apenas a capacidade de raciocinar por meio de um modelo analógico" (NERSESSIAN, 1992, p. 294). Nesse sentido, o raciocínio que realizamos em uma experiência de pensamento, ainda que possa fazer uso de representações e processos perceptivos, não implica a experimentação de uma imagem. Tal raciocínio é baseado em modelos análogos, não em imagens, os quais construímos através da imaginação a fim de simular uma situação real ou imaginária.

Dessa forma, ao construirmos e manipularmos modelos mentais estamos usando, além do nosso background de conhecimentos, informações derivadas de vários formatos representacionais, tais como o linguístico, o visual, o auditivo e o cinestésico, por exemplo. Também entram em jogo as representações que derivam de experiências do mundo real e de nossas conceituações delas. Sendo assim, conforme Nersessian (1992, p. 297):

a experimentação do pensamento é uma forma complexa de
raciocínio que integra várias formas de informação - proposições,
modelos e equações - em modelos mentais dinâmicos. Ao vincular
as dimensões conceituais e experienciais do processamento
cognitivo humano, a experimentação do pensamento demonstra
as consequências indesejáveis do mundo real de uma
representação, obrigando, assim, a mudança representacional.

Nesse sentido, para a autora, os experimentos de pensamento podem gerar novas informações ou conhecimentos sobre o mundo, pois ao serem bem-sucedidos em integrar 
essas várias dimensões podem produzir um modelo que nos permite acessar os dados que, embora contidos nas representações envolvidas em tal modelo, não estavam disponíveis até que o experimento de pensamento fosse executado em nossa mente. Ao vincular as dimensões conceituais e experienciais do processamento cognitivo humano, os experimentos de pensamento permitem que alcançamos certas conclusões, ou encontramos algumas contradições, sobre a situação que estamos avaliando que não seríamos capazes de constatar sem a integração das várias formas de informações que um modelo mental requer. A força epistêmica dos experimentos de pensamento vincula-se, assim, a uma capacidade há muito tempo presente nos seres humanos, a capacidade de imaginar e modelar a realidade. Ao experienciar mentalmente uma situação, através de um experimento de pensamento, além de estarmos lidando com tal capacidade que nos é elementar, podemos ter um ganho de compreensão, ou até mesmo de conhecimento, que não teríamos sem o auxílio dessa ferramenta de investigação.

\section{Experimentos de pensamento como recurso pedagógico}

Considerei até o momento o experimento de pensamento como sendo uma ferramenta importante para a investigação filosófica. Busquei explicar o que é essa ferramenta e como podemos obter novas informações através dela. Além disso, mencionei que os filósofos e cientistas utilizam experimentos de pensamento com o propósito de alcançar certas conclusões que podem corroborar ou refutar determinada teoria. Mas será que tal ferramenta metodológica poderia ser utilizada também como um recurso pedagógico? Será que ela pode contribuir para as aulas de Filosofia no ensino básico?

Os professores da disciplina de Filosofia no ensino básico têm dificuldade de estabelecer os conteúdos a serem trabalhados em suas aulas. Muito disso deve-se ao caráter aberto da própria disciplina, que não permite criarmos uma lista de resultados consensuais e apresentarmos aos alunos como conteúdos fechados e amplamente aceitos na comunidade filosófica ${ }^{6}$. O que muitos professores acabam fazendo é trabalhar a história do pensamento filosófico, ou por meio de temas como ética, política e epistemologia, por exemplo, ou apenas oferecendo uma apresentação cronológica dos autores dentro da sua classificação tradicional (antiga, medieval, moderna e contemporânea). Isso acontece porque para o conteúdo histórico da Filosofia existe um consenso, o que torna mais fácil a sistematização e apresentação desse conhecimento para os alunos. Mas a Filosofia não se resume à sua história. O que faz dela uma disciplina viva é a sua busca incessante por respostas aos mais variados problemas filosóficos. E esse lado da Filosofia é pouco apresentado aos alunos do ensino básico, uma vez que os problemas são inúmeros e não há consenso sobre eles, o que dificulta a criação de um programa de conteúdos comuns a serem trabalhados na disciplina.

Se queremos aproximar a Filosofia dos jovens, precisamos apresentar a eles esse lado vivo da disciplina, apresentar aquilo que a move enquanto área do conhecimento: 
seus problemas. Aproximar os alunos dos problemas filosóficos, muito mais do que da sua história, permite que os alunos compreendam o que é a própria Filosofia. A Filosofia não é apenas um amontoado de pensadores que, com suas frases bonitas, escreveram obras que parecem estar distantes da realidade dos próprios alunos. Através das aulas de Filosofia, podemos mostrar aos jovens que os problemas filosóficos estão presentes nos mais variados domínios da nossa vida e que a busca por respostas, ainda que o consenso possa nunca ser alcançado, é a parte mais instigante da Filosofia. Contudo, essa aproximação aos problemas filosóficos precisa ser feita com cuidado, uma vez que, em alguns momentos, ela requer a utilização de conceitos e pressupostos muitas vezes abstratos aos jovens iniciantes na disciplina. É nesse momento que os experimentos de pensamento podem servir não apenas como uma ferramenta de investigação, mas também como uma ferramenta que facilite a compreensão dos próprios problemas filosóficos e seus conceitos.

Desenvolver uma aula a partir da utilização de experimentos de pensamentos que encontramos na própria Filosofia, tal como aqueles mencionados no início do artigo por exemplo, permite que os alunos se encontrem na mesma posição que filósofos e cientistas, a de investigadores. Por meio da experimentação mental, os alunos podem percorrer cenários imaginários até então nunca percorridos por eles. Podem exercitar o papel de investigador e descobrir conclusões nunca antes consideradas por eles. Isso pode alimentar um sentimento de espanto e ao mesmo tempo de curiosidade, que motiva o pensar sobre o problema em discussão.

Quando o professor leva para a aula de Filosofia uma narrativa, um experimento de pensamento, ele trabalha com os alunos a capacidade de imaginação, já muito utilizada por nossos ancestrais para prever e avaliar uma situação, fenômeno ou ambiente. Desse modo, penso que fazer uso dessa capacidade, presente em nós a muito tempo, possa auxiliar os alunos na compreensão de problemas e conceitos mais facilmente do que se apresentados por meio de uma exposição tradicional, em que são descritos e definidos de modo rápido e abstrato pelo professor. Como sugere Nersessian (1992, 2018), os alunos, ao deparar-se com uma narrativa, criarão através da imaginação os seus próprios modelos mentais daquilo que está descrito, e utilizarão seus conhecimentos de fundo para modelar, atualizar e avaliar os modelos criados. O exercício mental proporcionado por um experimento de pensamento possibilita que os alunos lidem com conhecimentos tácitos e explícitos que eles não lidariam se apenas absorvessem uma informação já pronta, fornecida pelo professor. O raciocínio através de experiências de pensamento proporcionaria aos alunos um outro olhar para os problemas filosóficos. Eles não apenas absorveriam uma informação, mas teriam a possibilidade de, ao executarem um cenário imaginário, avaliar e tirar conclusões a partir disso. Os problemas tomam forma, ficam mais visíveis a partir da modelagem mental, e os conceitos envolvidos, ao fazerem parte do próprio modelo, podem ser melhor compreendidos pelos alunos.

Tomando como exemplo um dos três experimentos de pensamento apresentados anteriormente, podemos pensar em como ele pode aparecer em uma aula de Filosofia. Os casos desenvolvidos por Edmund Gettier (1963), por exemplo, podem surgir, assim como aconteceu para a própria epistemologia, como uma mudança no curso de uma aula que trata 
sobre o problema do conhecimento. Ao apresentar a definição tradicional de conhecimento para os alunos é possível que muitos deles não compreendam o que está em jogo quando o problema em questão é o conceito de 'conhecimento'. Mas acredito que quando forem solicitados a imaginar os casos hipotéticos de Gettier (1963) os alunos poderão lidar com o conceito de conhecimento de modo mais efetivo, e por meio da manipulação e experimentação mental poderão compreender o que está em jogo quando somos confrontados com uma situação em que precisamos julgar quando alguém sabe ou não alguma coisa. O que faz de uma pessoa alguém que sabe que algo é o caso? Por meio dos experimentos de pensamento os alunos poderão avaliar a situação, os sujeitos e os conceitos que estão envolvidos no caso em questão e lidar com perguntas como essas, por exemplo, de um modo mais natural, pois as respostas surgirão espontaneamente. Através da manipulação do modelo e da situação descrita no experimento de pensamento o aluno pode sozinho alcançar certas conclusões e compreensões que não alcançaria se as perguntas fossem realizadas sem essa vinculação com o experimento em si. Como recurso pedagógico, os experimentos de pensamento podem auxiliar os alunos a pensarem sobre os problemas e raciocinarem por meio de modelos mentais que, na medida em que eles mesmos os manipulam, possibilitam que a compreensão e até mesmo o ganho de conhecimento ocorram como consequência desse processo. Ainda que muitas vezes não seja possível abordar alguns problemas através dos experimentos de pensamento encontrados na própria Filosofia, penso que seria igualmente interessante que o professor utilizasse outros tipos de exemplos, narrativas, histórias fictícias, casos hipotéticos que sejam adaptados ao problema que ele pretende trabalhar. A ideia é que os alunos possam ser inseridos aos problemas filosóficos a partir desses recursos imaginativos e, com isso, possam experienciar mentalmente as situações e implicações que estão por trás desses problemas. Mediante essa experimentação do pensamento, podem utilizar capacidades cognitivas distintas para chegarem a uma compreensão do cenário e até mesmo a novas conclusões que podem ser extraídas desse processo de raciocínio. Nesse sentido, fazer uso de um experimento de pensamento como recurso pedagógico pode ser interessante, uma vez que o raciocínio envolvido em sua execução mental é uma tarefa complexa, como aponta Nersessian $(1992,2018)$, e requer do experimentador que várias informações e capacidades cognitivas sejam integradas para a criação e manipulação de um modelo. A vinculação de dimensões conceituais e experienciais do processamento cognitivo humano faz de uma experiência de pensamento não apenas uma boa ferramenta de investigação, mas também um proveitoso recurso pedagógico para ser utilizado nas aulas de Filosofia.

Trazer para as aulas de Filosofia recursos pedagógicos dos mais variados, tais como tecnologias digitais, recursos multimídia, websites, jogos, são tentativas de aproximar a Filosofia da realidade dos alunos. A Filosofia não precisa ser uma disciplina chata e pouco compreendida pelos jovens. Ela pode e faz parte dos questionamentos e problemas reais diários do ser humano. Precisamos, enquanto professores de Filosofia, apresentar essa vivacidade da atividade filosófica. Acredito que uma maneira de realizarmos isso seja trazendo os problemas filosóficos para a sala de aula e permitindo que os alunos pensem sobre e 
manejem tais problemas. Sugiro que um dos recursos que podemos utilizar nesse momento, que pode auxiliar os alunos a compreenderem tais problemas e lidarem com os conceitos filosóficos envolvidos, seja a ampla variedade de experimentos de pensamento encontrados na Filosofia. Além de servirem como uma ferramenta de investigação, também podem intermediar o processo de ensino e aprendizagem nas aulas de Filosofia do ensino básico.

\section{Considerações finais}

Pensar a disciplina de Filosofia no ensino básico como trabalhando problemas e conceitos requer uma base de conteúdos mais aberta, que permita aos alunos uma aproximação maior da própria atividade filosófica. Isso demanda dos professores novas alternativas que possibilitem a efetivação de uma proposta como essa. Uma das alternativas sugeridas é a utilização de recursos pedagógicos, dentre eles o uso de experimentos de pensamento durante as aulas de Filosofia. Tal ideia surgiu a partir da hipótese de que os alunos, por meio da experimentação mental de cenários imaginários, poderiam compreender melhor os problemas e conceitos apresentados pelo professor no decorrer de suas aulas. Para isso busquei investigar o que são experimentos de pensamento, qual o seu papel na investigação filosófica e como podemos explicar sua força epistêmica.

Nersessian $(1992,2018)$ oferece-nos uma concepção que busca, em estudos da ciência cognitiva, uma base para pensarmos sobre a força dos experimentos de pensamento e como eles funcionam. Suas considerações sobre o modo como raciocinamos por meio de experiências de pensamento reforçam a minha hipótese de que, além de ser uma ferramenta de investigação, um experimento de pensamento também pode servir como um valioso recurso pedagógico para as aulas de Filosofia. Nesse sentido, penso que fazer uso desse recurso pode ser uma alternativa instigante para aproximar os alunos da atividade filosófica e permitir que eles entrem em contato com a Filosofia em sua forma mais viva.

\section{Referências}

BROWN, James Robert. Laboratory of the Mind: Thought Experiments in the Natural Sciences. New York: Routledge, 1991a.

BROWN, James Robert. Thought Experiments: A Platonic Account. In: T. Horowitz and G. Massey (eds.), Thought Experiments in Science and Philosophy. Lanham: Rowman \& Littlefield, 1991b, p. 119-128.

CHALMERS, David. The Conscious Mind. Oxford: Oxford University Press, 1996.

CRAIK, Kenneth. The Nature of Explanation. Cambridge: Cambridge University Press, 1943.

FOOT, Philippa. The problem of abortion and the doctrine of the double effect. In: FOOT, Philippa: Virtues and Vices and Other Essays in Moral Philosophy. Oxford: Basil Blackwell, 1978. 
GENDLER, Tamar Szabó. Imaginary Exceptions: On the Powers and Limits of Thought Experiment. Dissertation. Harvard, New York: Garland Press, 1996.

GENDLER, Tamar Szabó. Intuition, Imagination, and Philosophical Methodology. Oxford: Oxford University Press, 2010.

GETTIER, Edmund. Is justified true belief knowledge?. Analysis, v. 23, 1963, p. 121-123. JACKSON, Frank. Epiphenomenal Qualia. Philosophical Quartely, v.32, 1982, p.127-136. JOHNSON-LAIRD, Philip. Mental Models. Cambridge: Harvard University Press, 1983.

KUHN, Thomas. A Function for Thought Experiments. In: KUHN, Thomas: The Essential Tension, Chicago: University of Chicago Press, 1977.

$\mathrm{MACH}$, Ernst. Über Gedankenexperimente. Zeitschrift für physikalischen und chemischen Unterricht, v. 10, 1897, p.1-5.

MURCHO, Desidério. A Natureza da Filosofia e o seu ensino. Educação e Filosofia, Uberlândia, v. 22, n. 44, 2008, p. 79-99.

NERSESSIAN, Nancy J. In the theoretician's laboratory: Thought experimenting as mental modeling. Philosophy of Science Association, v. 2, 1992, p. 291-301.

NERSESSIAN, Nancy J. Cognitive Science, Mental Modeling, and Thought Experiments. In: The Routledge Companion to Thought Experiments. New York: Routledge, 2018. p. 309-326.

NORTON, John. Are Thought Experiments Just What You Thought?. Canadian Journal of Philosophy, v. 26, 1996, p. 333-366.

NORTON, John. On Thought Experiments: Is There More to the Argument?. Philosophy of Science, v. 71, n. 5, 2004, p. 1139-1151.

ØRSTED, Hans Christian. Förste Indledning til den Almindelige Naturlaere, et indbydelsesskrivt til forelaesninger over denne vindenskab, (1811). Copenhagen (German translation): Über Geist und Studium der allgemeinen Naturlehre, In: Gehlens Journal für Chemie und Physik, vol. 36 (1822), p. 458-488.

PUTNAM, Hilary. The meaning of 'meaning'. In: GUNDERSON, K. (Ed.). Language, mind and knowledge. Minneapolis: University of Minnesota Press, 1975, p. 131-93.

RAWLS, John. A Theory of Justice. Cambridge: Belknap Press, 1971.

SEARLE, John R. Minds, Brains and Programs. Behavioral and Brain Sciences, v.3, n. 3, 1980, p. 417-457.

STUART, Michael T; FEHIGE, Yiftach; BROWN, James Robert. In: The Routledge Companion to Thought Experiments. New York: Routledge, 2018.

THOMSON, Judith. A defense of abortion. Philosophy \& Public Affairs, v. 1, n. 1, 1971. p. 47-66.

THOMSON, Judith. The trolley problem. The Yale Law Journal, 1985, v. 94, n. 6, p. 13951415. 


\section{Notas}

${ }^{1}$ Ver Ørsted (1811).

${ }^{2}$ Ver Mach (1897).

${ }^{3}$ Para um panorama amplo sobre experimentos de pensamento na história do pensamento filosófico, bem como em outras áreas do conhecimentos, ver The Routledge Companion to Thought Experiments (STUART; FEHIGE; BROWN, 2018).

${ }^{4}$ Esse questionamento aparece já em Kuhn (1977) e motiva as discussões sobre a capacidade informativa dos experimentos de pensamento científicos. Apesar da preocupação de grande parte dos autores que discutem esse problema voltar-se às experiências de pensamento na ciência, o problema também pode ser direcionado para a Filosofia. Uma versão desse problema na Filosofia é explicar como podem ocorrer mudanças conceituais significativas por meio de experiências de pensamento.

${ }^{5}$ Dentre eles podemos destacar os trabalhos desenvolvidos por James Robert Brown (1991a, 1991b) e John D. Norton $(1996,2004)$. Brown propõe uma concepção platônica sobre os experimentos de pensamento, ao considerar que adquirimos novos conhecimentos sobre as leis da natureza, por exemplo, através do acesso a um reino platônico. Esse acesso é possível em virtude de uma faculdade intuitiva que se revela por meio de experimentos de pensamento e nos permite acessar tais leis da natureza que seriam relações entre universais. A concepção de Norton, por outro lado, está encorada em uma visão empirista, que considera que todo nosso conhecimento sobre o mundo deriva da experiência. Para ele, experimentos de pensamento não operam nenhum milagre epistêmico, pelo contrário, eles nos dão conhecimento do mundo usando nossos recursos epistêmicos padrão, sendo, desse modo, apenas argumentos disfarçados em formas de narrativas, em que as conclusões extraídas deles seriam obtidas por meio de inferências dedutivas ou indutivas. Brown e Norton oferecem duas perspectivas muito distintas para o problema da aquisição de conhecimento por meio de experiências de pensamento. Entretanto, ambas parecem insuficientes quando aplicadas aos mais diversos tipos de experimentos de pensamento. Ainda que ambos os autores trazem algumas alternativas para compreendermos melhor os experimentos de pensamento de modo geral, nenhuma delas consegue nos oferecer uma explicação satisfatória para o poder epistêmico dos experimentos de pensamento. O raciocínio por meio da experimentação mental não parece ocorrer do mesmo modo que o raciocínio inferencial, como propôs Norton, uma vez que a conclusão de tal raciocínio parece emergir de modo rápido e espontâneo, não pressupondo passos inferenciais que demandariam um esforço cognitivo e de tempo maior. Como sugerido por Brown, a conclusão de um experimento de pensamento parece produto de uma capacidade intuitiva, o que poderia explicar a velocidade em que ela é alcançada. Mas pressupor que sua origem se encontra em um reino misterioso e que a atingimos apenas por meio dessa faculdade intuitiva, é algo implausível de ser defendido. Nesse sentido, precisamos encontrar uma perspectiva que consiga nos oferecer uma explicação razoável sobre o processo de raciocínio envolvido na experimentação mental e como tal processo é capaz de gerar novas informações, ou ainda, novos conhecimentos sobre o mundo.

${ }^{6}$ Podemos encontrar essa visão da Filosofia sendo defendida por Desidério Murcho (2008). O autor afirma que a Filosofia é uma disciplina em aberto, sem resultados substanciais consensuais. Além disso, ao refletir sobre o ensino de Filosofia, Murcho (2008) recomenda que deveríamos estimular e auxiliar o estudante a pensar por si nos problemas, teorias e argumentos que compõem a Filosofia.

\section{Correspondência}

Luana Francine Nyland - Av. Jorge Lacerda, 1668, Costeira do Pirajubaé , CEP: 88047-001, Santa Catarina, Brasil.

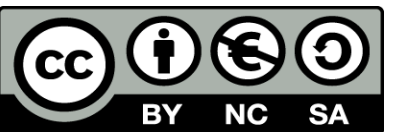

This work is licensed under a Creative Commons Attribution-NonCommercial 4.0 International (CC BY-NC 4.0) 